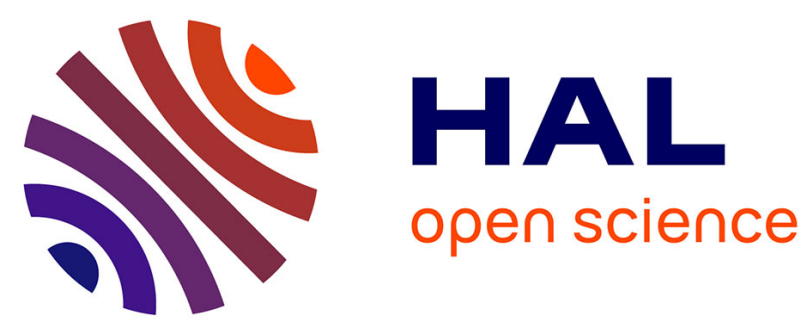

\title{
Modeling the spatial distribution of crop sequences at a large regional scale using land-cover survey data: A case from France
}

Ying Xiao, Catherine Mignolet, Jean-François Mari, Marc Benoît

\section{- To cite this version:}

Ying Xiao, Catherine Mignolet, Jean-François Mari, Marc Benoît. Modeling the spatial distribution of crop sequences at a large regional scale using land-cover survey data: A case from France. Computers and Electronics in Agriculture, 2014, 012, pp.51-63. 10.1016/j.compag.2014.01.010 . hal-00967890

\section{HAL Id: hal-00967890 \\ https://hal.inria.fr/hal-00967890}

Submitted on 31 Mar 2014

HAL is a multi-disciplinary open access archive for the deposit and dissemination of scientific research documents, whether they are published or not. The documents may come from teaching and research institutions in France or abroad, or from public or private research centers.
L'archive ouverte pluridisciplinaire HAL, est destinée au dépôt et à la diffusion de documents scientifiques de niveau recherche, publiés ou non, émanant des établissements d'enseignement et de recherche français ou étrangers, des laboratoires publics ou privés. 
Modeling the spatial distribution of crop sequences at large regional scale using land-cover survey data: a case from France

Ying Xiao ${ }^{\mathrm{a}^{*}}$, Catherine Mignolet ${ }^{\mathrm{a}}$, Jean-François Mari ${ }^{\mathrm{b}}$ and Marc Benoît ${ }^{\mathrm{a}}$

${ }^{a}$ INRA SAD UPR 055 ASTER, 662 Avenue Louis Buffet, 88500 Mirecourt, France

${ }^{\text {b }}$ Université de Lorraine, LORIA, UMR 7503, 54506 Vandoeuvre-lèsNancy, France

"Correspondingauthor. Address: INRA SAD UPR 055 ASTER, 662 Avenue Louis Buffet, 88500 Mirecourt, France. Tel.: +33 (0)329385500; fax: +33 (0)329385519. E-mail address: yingxiao0201@ gmail.com (Y. XIAO). 


\section{Abstract:}

2 Assessing the environmental impacts of agricultural production systems 3 requires spatially-explicit information of cropping systems.

4 Projectingchanges in agricultural land use caused by changes in land

5 management practices for analyzing theperformance of land-activities

6 related policies likeagricultural policies alsorequires this type of data as

7 model input. Crop sequences as a vital and widespread adopted agricultural

8 practice are difficult to be directly detected at regional scale. This study

9 presents an innovative stochastic Data Mining aimed at describing the spatial distribution of crop sequences at a large regional scale. The Data

11 Mining is performed by means of Hidden Markov Models and an unsupervised Clustering Analysis that processessequentially-observed(from 1992 to 2003) land-cover survey data of the French mainlandnamedTeruti.The 2549 3-year crop sequences were first identified as major crop sequences across the entire territory including 406 (merged) agricultural districts using Hidden Markov Models. The 406 (merged) agricultural districts were then grouped into twenty-one clusters according to the similarity of the probabilities of occurrences of major 3-year crop sequences by Hierarchical Clustering Analysis. Four cropping systems were further identified: vineyard-based cropping systems, maize monoculture and maize-wheat based cropping systems, temporary pasture and maize-based cropping systems and wheat and barley-based cropping systems. The modeling approach presented in this study provides a tool to extract largescale cropping patterns from increasingly available time series data of landcover and use.With this tool, users can (a) identify the homogeneous zone in terms of fixed-length crop sequences across a large territory; (b) understand the characteristics of cropping systems within a region in terms of typical crop sequences; and (c) identify the major crop sequences of a region according to the probabilities of occurrences.

\section{Keywords:}



models; Agricultural land-use; Teruti survey

\section{Introduction}

Today, $43 \%$ of the area of Europe (Eurostat, 2010) and 36\% of the world total area (FAOSTAT, 2011) are dominated by agricultural land use including both cropland and grassland. The current challenge for agronomists, farmers and their allied partners is to satisfy humanity's need for food and fiber as well as the accelerating demand for biomass in an ecologically sustainable way through socially accepted production systems (Miller, 2008).

In the land change science community, over the past decade, the scientific interest of investigating land-cover modification caused by the changes in land management practices has increasingly been noticed by researchers. As pointed out by Lambin et al. (2000), changes in agricultural land use management, e.g., changes in input levels and the effect on profitability, or the periodicity of complex land-use trajectories such as fallow cycles and rotation systems frequently drive land-cover modification. Incorporating into land system models the representation of agricultural land management practices and their changes will improve our understanding of the endogenous driving forces of land-cover modification. Several land system models integrate the module for simulating the farmers' management practice and decision processes (Rounsevell et al., 2003). Agent-based models were specially developed and applied to represent human behavioral and decisional processes in the land system (Matthews et al., 2007). As one of the most significant forms of land-cover modification, agricultural land intensification has recently been studied using different land-use intensity indicators such as livestock density and nitrogen input to UAA (utilized agricultural area) in relation to the land management practices (Herzog et al., 2006). For instance, Temme and Verburg(2011) mapped and modeled agricultural land use intensity in terms of nitrogen input at European Union 
scale. A multi-scale modeling approach for exploring the spatial-temporal dynamics of European livestock distribution was proposed by Neumann et al. (2011). However, crop rotations as a vital agricultural land management practice are rarely integrated into a land-use modeling framework at regional to global scale (Schönhart et al., 2011).

Crop rotations are defined as the practice of growing a sequence of crops on the same land (Wibberley, 1996). The term 'rotation' implies a cycle and it is characterized by the identified starter crops and the cycle period (e.g. biannual, triennial, 4-years, etc.) (Leteinturier et al., 2006). Because of the multiple benefits of the crop rotations such as increasing crop yields, decreasing the incidence of plant diseases and weeds, maintaining soil fertility, improving the soil structure, preserving biodiversity, crop rotations are a very old widespread practice. In the context of the establishment of new economic, agronomic and governmental policies, farmers will be paid for re-establishing and increasing ecosystem services on agricultural land (Miller, 2008). The positive effect of crop rotations has once more come to the notice of researchers(Merrillet al., 2012; Le Féonet al., 2013).

In the research community which assesses the environmental impacts of agricultural systems, modeling frameworks increasingly incorporated crop rotations instead of single crop for representing cropping patterns. These modeling approaches are related to nitrate leaching in intensive agriculture (Beaudoin et al., 2005), the impacts of agricultural management on the reduction of nitrogen content (Rode et al., 2009), the impact of farming on water resources (Graveline et al., 2012), etc. The manner of representing the cropping systems in terms of crop rotations in these studies was often simplified by expert knowledge based on their own specific field observation or interviews with farmers. A limited number of representative crop rotations were used for describing the cropping patterns in a spatial unit. For allocating these crop rotations within their study area, a crop rotation was usually stochastically assigned to a field, as in the study of Rode et al. 
91 (2009). This simplified approach of representing cropping patterns is due to

92 lack of information about the allocation of crop rotations(Rode et al., 2009).

93 Furthermore, 'crop generator' was proposed for producing spatial and

94 temporal crop distribution under certain conditions such as soil types,

95 agronomic rules or expert knowledge and possiblycalibrated with observed

96 data (Dogliotti et al., 2003; Schönhart et al., 2011). A crop generator was

97 included as an additional module in several hydrological models

98 (Wechsunget al., 2000; Klöckinget al., 2003). The shortcoming of

99 agronomic rules-based crop generators is due to they generate theoretical

100 crop rotations according to the agronomic suitability, but the real crop

101 rotation practices at the field level is influenced by economic condition in

102 the first place, biophysical conditions play only a secondary role (Klöcking

103 et al., 2003). Meanwhile, a study of uncertainty in simulation of nitrate

104 leaching at large regional scale points out the lack of information on the

105 agricultural landuse management presents the greatest uncertainty and

106 underlines its importance (Schmidtet al., 2008). All these reviewed

107 modeling approaches represented cropping patterns from the field to

108 regional meso scale. For representing the cropping patterns at large regional

109 scale or global scale, no modeling work is proposed in the literature. As

110 opposed to the existence of various models at field scale for designing

111 sustainable cropping systems, the lack of cropping system models at

112 regional or global scale results from the unavailability of spatially and

113 temporally explicit information on crop rotations and their associated crop

114 management system (Therond et al., 2011).

115 The aim of our study is topresent an innovative stochastic Data Mining

116 methodology for describing the spatial distributionof crop sequences at a

117 large regional scale. The Data Mining is performed by means of Hidden

118 Markov Models and an unsupervised Clustering Analysis that

119 processessequentially-observed(from1992 to 2003) land-cover data of the

120 French mainland. 
121 Our study can be considered as an empirical analysis of historical cropping

122 patterns at a large regional scale which will contribute to the scenarios

123 creation of agricultural land-use change caused by changes in land

124 management practices for analyzing the performance of land-activities

125 related policies and land planning.It also provides a tool to extract large-

126 scale spatially-explicit data of cropping patterns from increasingly available

127 time series data of land-cover and use, which will improve the accuracy of

128 the assessment of environmental impacts of agricultural systems. In this

129 study, we define 'crop sequences' as the order of appearance of the crops

130 during a fixed period. Crop sequences are strictly synonymous with crop

131 successions. They are the partial or total development of a cycle of rotation

132 or even the basis of several cycles (Leteinturier et al., 2006). As pointed out

133 by the field survey based study, farmers grow different crops over the years

134 in their farm fields without necessarily designing strict rotations (Joannon et

135 al., 2008). For a study of cropping patterns at national scale, we limit our

136 investigation to the major crop sequence related cropping patterns.

137 We present our modeling approach as follows. First, we describe our study

138 area and the available data source of land-cover. Next, we make a brief

139 introduction of the temporal data mining tool. We then apply our modeling

140 approach, using this historical national land-cover survey data for clustering

141 the French agricultural districts in terms of the similarity of occurrences of

142 crop sequences. Finally, we further characterize the clusters of agricultural

143 districts using both the typically regional crop sequences and the major crop

144 sequences of a region.

\section{2. Materials and Methods}

1462.1 Study area

147 Our study area is the French mainland (the island of Corsica is not included)

148 in Western Europe covering 552 thousand square kilometers. Agricultural

149 area as part of the total land area in mainland France was 55.4\% in 1992 and

$15054.2 \%$ in 2003 (FAOSTAT, 2011). The area of main agricultural land use at 
151 the beginning and end of our study period is described in Table 1. Because

152 of the variation of environmental and socio-economic conditions across the

153 entire territory, the French agricultural production systems reveal their

154 regularity on the spatial distribution. Fig. 1 describes the spatial distribution

155 of farm typology based on the community typology of agricultural holdings

156 in France in 2000 which was carried out by the French Ministry of

157 Agriculture. This EU farm typology is based on economic criteria such as

158 economic size and type of farming. It gives us a glimpse of the spatial

159 distribution of farming systems across French territory. The main cropping

160 zone for cereal and oilseed production is located in central, northern and

161 southwestern France. The livestock zone is situated mainly in the north-west

162 and the Massif Central of France. The mixed cropping and livestock zone is

163 located mainly in southwestern France.

Table 1

Fig. 1

2.2 Data source

167 The sequential land-cover data used in this study was derived from Teruti databases. Teruti is a two-level sampling survey of land-cover conducted by the French Ministry of Agriculture (Ledoux and Thomas, 1992). Fig. 2 illustrates the sampling method performed in this survey. At the first sampling level, the whole territory was segmented into 4700 grids with an area of $12 \times 12 \mathrm{~km}$ per grid (Fig. $2 \mathrm{a}$ ). In most regions, 4 aerial photos among 8 at the positions numbered in 1, 2, 3, 4 (Fig. 2b) were taken within each grid. In total, 15579 aerial photos were taken every June during the survey period. One aerial photo covers around 3.24 square kilometers. At the second sampling level, 36 evenly-spaces sampling points (approximately

$177300 \mathrm{~m}$ apart) were systematically distributedwithin the area of one aerial photo (Fig. 2c). The land-covers of the entire territory were recorded in a matrix in which the sampling points are in a row and the annual records of land-cover in a column. A corpus of 555,382 sampling points labeled with 
181 their land-cover during the period from 1992 to 2003 was used in this

182 study.It has detailed information on 81 types of land-cover, including 41

183 types of crops. Moreover, the Teruti survey provides the constant sampling

184 points which ensure representativeness at different spatial scales based on

185 the occurrences and richness of crops.

Fig. 2

187 We chose the French agricultural district as the spatial unit in this study.

188 This zoning was established by the French Ministry of Agriculture in 1946

189 mainly according to the homogeneous agricultural activities and partly the

190 similar environmental conditions such as soil profile and climate (Richard-

191 Schott, 2009). The study by Mignolet et al. (2007) based on interviews with

192 the regional chambers of agriculture indicates that after more than 50 years

193 of development of the socio-technical system, the principal agricultural

194 activities within an agricultural district have remained homogeneous in the

195 Seine Basin. Thus the level of aggregation of Teruti sampling points was

196 defined with respect to the zoning of the agricultural district. All of the 430

197 agricultural districts in the French mainland territory were incorporated into

198 this study. Because of the small quantity of sampling points (less than 100

199 points per district) in 21 agricultural districts, we merged them into one of

200 their neighborhood districts according to the similarity of the main land-

201 cover categories. Finally, 406 spatial units including 384 individual

202 agricultural districts and 22 merged agricultural districts were studied.

$203 \quad 2.3$ Overview of methods

204 Our strategy of modeling the spatial distribution of crop sequences is to 205 classify the agricultural districts according to the similarity of the 206 occurrences of crop sequences and further to map the result of clustering.

207 The modeling work was carried out in three steps. Firstly, temporal data

208 mining software was applied to estimate the probabilities of the occurrences

209 of crop sequences within each spatial unit. Secondly, we grouped the spatial

210 units in terms of similar crop sequences by performing a classic non- 
211 supervised clustering technique. Finally we mapped the result of clustering

212 with the aid of ArcMap 10. In this section we first make a brief introduction

213 of CARROTAGE, our temporal data mining tool used to extract the land-

214 use successions (LUS) in each (merged) agricultural district. We then

215 describe the procedure for identifying the major crop sequences within 406

216 spatial units using this tool. Finally, the non-supervised classification of the

217 agricultural districts and the cartography of the clustering result will be

218 presented. Here, we take the entire French mainland as a spatial unit for

219 example to demonstrate the procedure of identifying the crop sequences

220 using CARROTAGE. In our analysis, the identification of major crop

221 sequences within a (merged) agricultural district was individually done in

222 the same way for all 406 (merged) agricultural districts.

223 2.3.1 Description of the temporal data mining tool

224 CARROTAGE(Le Ber et al., 2006; Mari and Le Ber, 2006), which is a free 225 software,was used to extract the crop sequences on the Teruti survey 226 databases.

227 Different from several published modeling frameworks of crop sequences which use first-order Markov chains(Aurbacher and Dabbert, 2011;

229 Castellazzi et al., 2008;Salmon-Monviolaet al., 2012), CARROTAGE implements second-order Hidden Markov Models (HMM2). The Hidden

231 Markov Models (HMM) represent the variability inherent to land-cover by means of land-cover distributions organized in a Markov chain rather than representing distinct Markov chains of land-cover. In a HMM2, the Markov chain is a second-order Markov chain that governs the sequence of landcover distributions. This makes more precise modeling of time events possible, since the land-cover distribution at year $t$ depends upon the crop grown in year $t-1$ and also $t-2$. Experiment results in speech recognition indicate that HMM2 provides better duration modeling than HMM1 (Mari and Le Ber, 2006). The main feature of HMM of any order is the existence 
241 parameters using a corpus of land-cover sequences (the training corpus).

242 2.3.2 Identification of major land-cover categories within a spatial unit

243 The first step in data mining is to find an adequate way of encoding the data.

244 We performed a temporal segmentation of the huge matrix of land-cover

245 that covers the period 1992-2003 in order to reduce the number of columns

246 and to represent each sub-period by the distribution of land-cover occurring

247 in this sub-period. Following Le Ber et al. (2006), we specified 12 states

248 left-right HMM2 with one-year land-cover as observation symbol. As our

249 study period covers 12 years, the initial number of states defined for the first

250 specified HMM2 was therefore 12. This HMM2 was trained using the whole

251 matrix and gave 12 land-cover distributions. Among these 12 distributions,

252 many of them were similar. By reducing the number of states, step by step,

253 we got 5 different distributions that defined 5 different land-cover

254 distributions. In this way, crops such as bean, oats, fiber crops, rye, etc.

255 which were not principal crops with extensive growing areas during the

256 whole period but dominant in the territory in several sub-periods, could be

257 incorporated in the study. This procedure of identifying main land-cover

258 using temporal segmentation is useful for us to define which crops will be

259 incorporated into our investigation of crop sequence patterns considering the

260 diversity of crops.

261 We defined major land-cover types as those types which represented at least

$2621 \%$ of frequency among the total number of land-cover records in the

263 dataset. And all major land-cover types identified in all of the 5 states were

264 then retained as main land-cover categories of a spatial unit for the next

265 analysis of the land-use succession (LUS). Table 2 outlines the main land-

266 cover types identified in these 5 states. Considering the goal of this study

267 was to investigate the crop sequence patterns, we kept crops (except for

268 artificial pasture and temporary pasture) in individual categories and

269 grouped several other land-cover types in one category according to their 
270 similarities of characters in land systems (more details see Table 3). Finally,

27112 major land-cover categories (Table 3) were defined and were further

272 used for studying LUS.

273

274

275

276

277

278

279

280

281

282

283

284

285

286

287

288

289

290

291

292

293

294

295

296

297

298

299
Table 2

Table 3

2.3.3 Extraction of all LUS involving the major land-cover categories

CARROTAGE allows users to specify HMM2 that can process either single land-cover sequences or sequences made of overlapping fixed length landcover sub-sequences. For example, the 12 year land-cover sequence: rapeseed-wheat-barley-rapeseed-wheat-barley... can be parameterized into a sequence of 11 overlapping 2-year land-cover sub-sequences: rapeseedwheat, wheat-barley, barley-rapeseed... or even by 10 3-year land-cover sub-sequences: rapeseed-wheat-barley, wheat-barley-rapeseed, barleyrapeseed-wheat... The longer the length of the sub-sequence (say $n$ ), the more different $n$-uplets we have. This leads to under-training issues when the Baum-Welch algorithm estimates the distributions. On the other hand, the greater $n$ is, the more interesting it is for agronomists to find out long crop sequences. In order to choose a suitable observation symbol, we made reference to the previous research work of Le Ber et al. (2006) and Mignolet et al. (2007) in the Seine Basin, where the main field crop cultivation zone in France is located, and to the national statistics published by the French Ministry of Agriculture on farming systems (Agreste, 2010). The former study confirms that crop sequences within the Seine Basin are frequently organized in three or four years. The national agricultural statistics indicate that the crop sequences implemented on French territory generally consist of three times wheat and/or barley and once or twice special regional crops. Considering all the above factors, we choose 3-year land-cover subsequence as the elementary observation symbol in this study.

Referring to the work of Lazrak et al. (2010), we applied a search pattern (Table 4) for extracting all 3-year LUS involving a given major land-cover 
category. As the field rotation system based on 'three-field rotation' and 'Norfolk four course system' are widely implemented in Western Europe (Molnar, 2003), we further introduce a field-adopted agronomic rule: starter crop to define the search pattern. The starter crops are often the precedent crop of wheat (mainly) or barley. The field residues of these crops play an important role for soil organic matter and $\mathrm{P}$ and $\mathrm{K}$ fertilizers restoration. The specialization of starter crops in different agricultural districts constitutes the base of the diversification of cropping patterns while wheat and barley is ubiquitous. Table $4 \mathrm{a}$ shows the search pattern we used for extracting the LUS involving these 5 main starter crops in France: maize, rapeseed, peas, sunflower and sugar beet. For the other land-cover categories, the search pattern shown in Table 4b was performed. The introduction of the search patterns in form of 'starter crop-wheat' can be considered as a use of HMM2 in a supervised way. In comparison to using one major crop involved search pattern (Lazrak et al., 2010), the search pattern 'starter cropwheat' avoids the repetitions of the same 3-year LUS in different Dirac states (states within HMM2 whose distribution are zero except on a given land-cover category). It keeps the non-agronomical sustainable crop sequences but still implemented in practice like successive cultivation of maize, wheat in a separate state 'container state' (state associates to all the other less frequent land-cover categories). It thus gives a better result.

\section{Table 4}

One-column ergodic HMM2 (all transitions between states are possible) was performed to carry out this extraction of 3-year land-use successions. The number of Dirac states of model depended on the major land-cover categories previously identified plus a container state (Le Ber et al., 2006).

\subsubsection{Filtration of major crop sequences from all 3-year LUS}

The goal of this task is to filter out the major 3-year LUS including 3-year successive crops (it means crop sequences in our study) in the output of onecolumn ergodic HMM2 obtained previously. 
330 We first filtered the 3-year LUS in each Dirac state in the CARROTAGE

331 output files of a spatial unit using double criteria: at least $1 \%$ of the

332 probability of occurrence and the appearance of the given land-cover

333 categories in the 3-year LUS. For the container state, all of the LUS which

334 had at least $1 \%$ of the probabilities of occurrences were kept for the next

335 step. As the aim of our study was to investigate the major crop sequence

336 related cropping patterns at national scale, a large number of 3-year LUS

337 were removed using the threshold of $1 \%$ of the probability of occurrence.

338 Next, the 406 individual records of main LUS of a (merged) agricultural

339 district were used to build an inventory table in which the 3437 LUS were in

340 a column and the 406 agricultural districts were in a row. In this inventory

341 table, we further removed 888 land-use successions including non-crops in

342 3-year successions. The remaining 2549 3-year land-use successions, strictly

343 including three successive years of crops, called 'crop sequences' in this

344 study, were retained to cluster 406 (merged) agricultural districts.

345 Finally, in order to facilitate the interpretation of the characteristics of crop

346 sequence patterns by understanding the context of the agricultural land use,

347 we reclaimed 11 land-use successions which were relevant to the perennial

348 land categories from the 888 removed land-use successions. They were 3-

349 year successions of forest, natural pasture, grass orchard, Alpine meadows,

350 herbaceous vegetation area, rocky areas, water bodies, other semi-natural

351 areas, vegetable gardens and artificial areas with and without construction.

352 Thus, the probabilities of occurrences of 2549 3-year crop sequences and 11

353 perennial land-covers were retained as the parameter vector of the 406

354 (merged) agricultural districts.

355 2.3.5 Clustering and mapping agricultural districts in terms of homogenous

356 crop sequences

357 In order to cluster the 406 (merged) agricultural districts, we chose the

358 Principal Component methods prior to Ward's Agglomerative Hierarchical

359 Methods (AHC) according to Euclidean distance (Husson et al., 2010) using 
360 R software (R Core Team, 2012) 'FactoMineR' package (Lê et al., 2008).

361 Performing PCA on the raw data is an efficient technique for avoiding high

362 correlations between variables. In our case, taking a typical 3-year 'wheat-

363 barley-rapeseed' crop rotation as an example, the occurrences of its three

364 forms "rapeseed-wheat-barley", "wheat-barley-rapeseed" and "barley-

365 rapeseed-wheat" should be strongly correlated. Thus performing PCA can

366 be considered as a preprocessing of the crop sequence data. It can improve

367 the robustness of the clustering analysis (Josse and Husson, 2012). The PCA

368 was performed without the use of standardization of variables, since the 3 -

369 year crop sequences were measured on scales without widely differing

370 ranges and the units of measurement are the same.

371 In addition, in PCA, 2549 crop sequences were used as active variables and

37211 perennial land-covers were used as supplementary variables. The

373 AHCwas performed on the first principal components which account for $80 \%$

374 total inertia. In order to choose the suitable number of clusters in AHC, we

375 first defined the least possible and the most possible number of clusters

376 according to the evident drop in the bar graph of the distance values which

377 was drawn using the package "Cluster" within R. Next, we determinedthe

378 suitable number of clusters within the range of the least and most possible

379 number of clusters with the aid of R software (R Core Team, 2012) 'clValid'

380 package (Brock et al., 2011).All six measures relevant to 'internal' and

381 'stability' measures implemented in 'clValid' package were used to validate

382 the number of clusters. This number of clusters was then used as argument

383 in the function 'HCPC' of 'FactoMineR' for performing AHC. The

384 advantage of using FactoMineR is that the package integrates a function of

385 the description of clusters by all initial continuous variables both active and

386 supplementary. This measure is named v.test(Lebart et al., 1995), which can

387 be considered as a "standardized" deviation between the mean of those

388 individuals with category $q$ and the general average (Husson et al., 2010). In

389 order to understand the characteristics of clusters, the probabilities of 
occurrences of major 3-year crop sequences were estimated by performing one-column ergodic HMM2 on the corpus of Teruti land-cover data of the agricultural districts belonging to one cluster. The one-column HMM2 contained one Dirac state involving all non-crop land-cover using search pattern (Table $4 b)$.

Finally, the result of clustering analysis was mapped with the aid of ArcMap10 to visualize the crop sequence patterns during 1992-2003.

In addition, while the classification of agricultural districts was established, we further explored the major non-fixed length crop sequences in the territory of one cluster with the aid of the graphic output of one-column ergodicHMM2 (Le Ber et al., 2006).

\section{Results}

\subsection{Descriptive statistical analysis}

In PCA, the first two components explained $23.8 \%$ and $12.3 \%$ of the total inertia, respectively. The first twenty-three principal components which accounted for $80.1 \%$ of total variability were used to cluster the agricultural districts. Two-dimensional PCA scores plots and loading plots on PC1 vs. PC2 and PC3 vs. PC4 are shown in Fig. 3. The agricultural districts score plot for PC1 vs. PC2 (Fig. 3a left) reveals two distinguished groups of agricultural districts. One group is projected on the negative dimension of PC1. According to the loading plot of crop sequences (Fig. 3b left), the occurrence of vineyard contributes most to this observed clustering. Another group is projected on the positive dimension of PC2 which correlates with the occurrence of wheat-based crop sequences. In the scores plot of agricultural districts of PC3 vs. PC4 (Fig. 3a right), three groups can be observed. The sugar beet-based crop sequences are heavily loaded for PC4 (Fig. 3b right) which separates the group projected on the negative dimension of PC4 from the others. The second group is projected on the positive dimension of PC4 which can be explained by the sunflower-wheatbased crop sequences having high value of occurrences for PC4 loading. 
420 The occurrence of monoculture of maize is most strongly responsible for the

421 discrimination of one group of agricultural districts that is projected on the

422 positive dimension of PC3. And the occurrence of 3-year fallow partly takes

423 responsibility for this discrimination.

Fig. 3

$425 \quad 3.2$ Clustering (merged) agricultural districts

426 At the first step, we used a visual aid, the bar graph of the distance values

427 (Fig. 4) to determine a wide range of the number of clusters. This distance

428 value was the distance value between the two joining clusters that was used

429 by the Ward's method. We looked for the jumps in the decreasing pattern in

430 this bar chart. One possible drop occurs at about the number of clusters $=11$

431 and another occurs at 25. That is, the differences of height between two

432 sizes of clusters after them are all relatively small and about the same size.

433 Next, adopting the cluster validation measures approach implemented in the

434 clValid Package of Brock et al. (2011), we determined the most appropriate

435 number of clusters within the range of 11 to 25 . Table 5 shows the result of

436 internal and stability measurements based on different sizes of cluster.

437 Results from the 7 indices indicated that the number of clusters $=21$ perhaps

43823 was suitable. Considering the tiny differences of the order of crop

439 sequences and their v.test value between the two new small clusters which

440 belonged to the same original cluster, we finally took 21 as the appropriate

441 number of clusters for the AHC. Fig. 5 is the visualization of the result of

442 clusters mapped with ArcMap.

Fig.4

Fig. 5

$446 \quad 3.3$ Description of the crop sequence patterns

447 The crop sequence patterns delimited in Figure 5 can be described by both

448 the v-test values obtained as outputs of the function HCPC within 
449 FactoMineR and the probabilities of occurrences of major 3-year crop

450 sequences (Table 6).

452 Based on the ten most frequent 3-year crop sequences identified in each 453 cluster, four types of crop sequence patterns can be identified. The first type 454 was vineyard-based cropping systems and it included the clusters 1, 2, 3, 4, $4555,6,8$ and 12 . The second type was characterized by the predominance of 456 maize monoculture and maize-wheat-based crop sequences. Clusters 7, 13, 45715 and 16 belonged to this type. The third type was temporary pasture and 458 maize-based cropping systems possible for livestock. It included clusters 9, 45910 and 11. The fourth type was wheat and barley-based cropping systems 460 including the clusters 14, 17, 18, 19, 20 and 21. This pattern of agricultural

461 districts has been revealed in the previous PCA. Here, we further describe 462 these 21 clusters with the aid of v.test value.

$463 \quad$ 3.3.1 Vineyard-based cropping systems

464 Four types of vineyard-based cropping systems were distinguishable. The 465 presence of other cropping systems discriminated them. The areas of 466 clusters $1,2,4$ and 12 were characterized by the predominant mixed systems 467 of vineyard for wine and grape production and other fruit production. Maize 468 monoculture and 3-year successions of sown pastures also occurred in this 469 zone. The differences among these clusters were the occurrences of different 470 fruits which are managed as permanent crop areas. For example peaches and 471 apricots were widely grown in the agricultural districts of cluster 1. Apples, 472 pears and plums were dominant in the zone of cluster 2. Other species of 473 fruits were grown as speciality crops in clusters 4 and 12 . Furthermore, 474 monoculture of durum wheat was an important characteristic of the cropping 475 systems of cluster 4. Cluster 3 is the second type of vineyard-based cropping 476 system. Vineyard was absolutely predominant in the agricultural districts of 477 this cluster while maize monoculture and maize-fallow-based crop 478 sequences were also broadly implemented. Clusters 5 and 6 can be 
479 identified as the third type of vineyard-based cropping system where

480 vineyards were less frequent than in the zone of cluster 3. And it co-existed

481 with wheat and barley incorporating oilseed crops and sugar beet-based

482 cropping systems. The appearance of beans and artificial pasture based on

483 alfalfa in 3-year crop sequences was a remarkable characteristic of cluster 6.

484 A small cluster (cluster 8) involving 4 agricultural districts was revealed as

485 the fourth type of vineyard-based cropping system. The occurrences of

486 monoculture of durum wheat and other industrial crops discriminated this

487 cluster from the others.

488 3.3.2 Maize monoculture and maize-wheat-based cropping systems

489 Maize monoculture was the dominant crop sequence within the agricultural

490 districts of cluster 13. Fallow and vegetables were often integrated into the

491 maize-based crop sequences in this zone. Clusters 7, 15 and 16 belonged to

492 another type of maize-based cropping system. The surface of maize

493 monoculture was important while maize-wheat-based crop sequences and

494 oilseed crops (sunflower and rapeseed)-wheat-based sequences also took a

495 great proportion of growing areas.

$496 \quad$ 3.3.3 Temporary pasture and maize-based cropping systems

497 Three big clusters 9, 10 and 11 including in total 137 (merged) agricultural

498 districts were characterized by the widespread adoption of successive

499 temporary pasture and temporary maize crop sequences. Maize and wheat-

500 based crop sequences and maize monoculture frequently occurred in the

501 zone of clusters 9 and 10. The high values of v-test of three supplementary

502 variables relevant to the occurrences of rocky areas, alpine meadows and

503 herbaceous vegetation area highlighted that the temporary pasture and

504 maize-based cropping systems in the zone of cluster 11 were probably very

505 extensive and different from the temporary pasture and maize-based

506 cropping systems of clusters 9 and 10. The small cumulative probabilities of

507 occurrences of the 10 most frequent 3-year crop sequences pointed out that

508 arable land under a rotational system occupied a small surface and the 
509 extensive area of cluster 11 for agricultural land use was natural permanent

510 grassland.

511 3.3.4 Wheat and barley-based cropping systems

512 Six clusters including 115 (merged) agricultural districts belonged to this

513 type of cropping systems. Cluster 14 was the specialist of sunflower

514 cultivation and sunflower was often grown between two years of cereals.

515 The speciality of clusters 17 and 18 was rapeseed. Probably, a typical 3-year

516 "wheat-barley-rapeseed" rotation which consists of three forms: "wheat-

517 barley-rapeseed", "barley-rapeseed- wheat" and "rapeseed-wheat-barley"

518 was broadly adopted in the zone of these two clusters. We can observe that

519 maize-wheat-based crop sequences occurred frequently in the zone of

520 cluster 17 . The presence of 3 -year successions of the cultivation of wheat

521 and/or barley discriminated cluster 18 from cluster 17. The "wheat-barley-

522 rapeseed" rotation was also implemented in the zone of cluster 19 and 21.

523 The appearance of pea or sugar beet in 3-year wheat and barley-based crop

524 sequences was an important characteristic of the cropping systems of these

525 two clusters. One remarkable crop sequence that discriminated cluster 21

526 from 19 is the 3-year sequence of nurseries. The introduction of sugar beet,

527 peas or potatoes between two years of wheat and/or barley was an important

528 characteristic of the cropping systems of cluster 20. The 4-year "wheat-

529 sugar beet- wheat- peas" sequence probably rotated during the study period

530 in the zone of cluster 20.

5313.4 Exploration of major non-fixed length crop sequences: example of 532 cluster 17

533 The major land-cover categories in the thirty agricultural districts of cluster

53417 were: wheat, barley, rapeseed, maize, sunflower, temporary pasture,

535 fallow, grassland, other semi-natural zone and perennial areas. One-column

536 ergodicHMM2 with 9 Dirac states and one container state was thus

537 performed. Figure 6 is the graphic output of model in which the

538 probabilities of transitionsbetween two land-cover categories are expressed 
539

540

541

542

543

544

545

546

547

548

549

550

551

552

553

554

555

556

557

558

559

560

561

562

563

564

565

566

567

568

by the width of the line joining the two land-covers.One can see that, the major crop sequencs are:

(1) Three-year crop rotation "wheat-barley-rapeseed" which consists ofthree 3-year sequences strictly rotating during the whole study period : "barley-rapeseed-wheat" (shown in Fig. 6b by polyline "B1-C2-A3-B4C5-A6-B7-C8-A9-B10-C11-A12”), “wheat-barley-rapeseed” (polyline “A1-B2-C3-A4-B5-C6-A7-B8-C9-A10-B11-C12”), and “rapeseedwheat-barley" (polyline “C1-A2-B3-C4-A5-B6-C7-A8-B9-C10-A11B12”);

(2) Two-year strict crop rotation "maize-wheat" which consists of two rotating 2-year sequences “maize-wheat” (polyline "D1-A2-D3-A4-D5A6-D7-A8-D9-A10-D11-A12”) and “wheat-maize” (polyline “A1-D2A3-D4-A5-D6-A7-D8-A9-D10-A11-D12”);

(3) Two-yearcrop rotation "rapeseed-wheat" which consists of two rotating 2-year sequences "rapeseed-wheat" (polyline "C1-A2-C3-A4-C5-A6C7-A8-C9-A10-C11-A12”) and "wheat-rapeseed" (polyline “A1-C2-

$$
\text { A3-C4-A5-C6-A7-C8-A9-C10-A11-C12”); }
$$

(4) Monoculture of maize (line D1D12), wheat (line A1A12), and barley (line B5B12);

(5) Long-term fallow (lines F1F4 and F5F10), and temporary pasture (line G1G2);

(6) Two-year sequences "rapeseed-wheat" and "maize-wheat" and one year of wheat may interrupt the predominant 3-year crop rotation "wheatbarley-rapeseed" like "barley-rapeseed-wheat-rapeseed-wheat- barleyrapeseed-wheat- barley-rapeseed-wheat-" (polyline "B1-C2-A3-C4-A5B6-C7-A8-B9-C10-A11-”), “rapeseed-wheat-barley- rapeseed-wheatbarley- rapeseed-wheat-maize-wheat-barley-rapeseed" (polyline " $\mathrm{C} 1$ A2-B3-C4-A5-B6-C7-A8-D9-A10-B11-C12”) and "wheat-barleyrapeseed-wheat-barley-wheat-barley-rapeseed-” (polyline “A1-B2-C3A4-B5-A6-B7-C8-"), respectively. 
569 One important point has to be noticed is that we can identify the occurrence

570 of major unfixed-length crop sequences, even the exact crop rotations within

571 a spatial unit, but the rate of their occurrences is impossible to be quantified.

572

573

574

575

576

577

578

579

580

581

582

583

584

585

586

587

588

589

590

591

592

593

594

595

596

597

598

Fig. 6

\section{Discussion}

4.1 A generic approach to describe regional time-space regularities in agricultural landscape

The modeling approach presented in this paper provides a tool to derive spatially-explicit data of cropping patterns at large regional scale from the sequential annual land-cover survey data. With this tool, users can (a) identify the homogeneous zone in terms of fixed-length crop sequences across a large territory, (b) understand the characteristics of cropping systems within a region in terms of typical crop sequences, (c) identify the major crop sequences of a region according to the probabilities of occurrences, and (d) identify the most representative spatial units of each cluster.

The potential application of this modeling approach is as a tool to extract spatially-explicit information on cropping patterns from time series data of land-cover for environmental or economic assessment of agricultural production systems. It can also be used for building historical data of cropping patterns which can be integrated into the land-use change modeling framework for land planning and policy making.

4.2 Limitations of crop sequence- based modeling

The approach proposed here however, has several limitations. These limitations are mainly due to the simplified representation of the complex rotational cropping system. First, we took the concept 'crop sequences' which is limited to the order of appearance of the crops during a fixed period instead of the exploration of the exact cycle of crop rotations during the study period. Indeed, most agricultural land management practices are decided at the local scale by the farm holders under different biophysical 

that farmers grew the crops in a field of their farm over the years without implementing strict crop rotations keeping a degree of freedom in their choices. This may explain why a great number of crop sequences can be observed over a large area. Two observation-based studies confirmed this point. Leteinturier et al. (2006) observed 62499 7-year crop sequences in an area of 255,461 hectares in the Wallonia area of Belgium. In another study in the Central United States, there were 24 crops observed in database and a total of 9,826,083 4-year crop sequences occurred from 2003 to 2010 (Plourde et al., 2013).

609 Secondly, as we adopted the temporal regularity mining tool based on

610 Hidden Markov Models, we needed to define an observation symbol for the 611 model. In our case, the observation symbol is crop sequence that consists of 612 three components: the length of sequence, the appearance of crops and their 613 order. Our strategy of modeling the spatial distribution of crop sequences is 614 to classify the agricultural districts based on the occurrences of crop 615 sequences within each spatial unit and further mapping the result of 616 clustering. Thus, in order to explore the major crop sequences within each 617 spatial unit, we need to define unique length of sequence for all land units 618 studied. But as we know, in reality, the length of crop rotations ranges from 6192 years to 12 years (long crop rotations are often observed in organic 620 farming) (Mudgal and Lavelle, 2010). Hence diversity of crop rotations in 621 terms of the rotation length has been ignored in this study.

622 Thirdly, based on expert knowledge, we chose 3-year crop sequence as our 623 observation symbol for all 406 (merged) agricultural districts. But the fixed624 length crop sequences do not mean a great simplification of complex crop 625 sequences in reality. As monoculture and biennial, triennial and quadrennial 626 crop rotations are widely adopted in the field cropping area for cereal and 627 oilseed production in French mainland. Although this choice of the length of crop sequences may be unable to cover the complete cycles based on the 
629 long rotations, biennial, triennial and partly quadrennial rotations covers

630 most areas of arable land. Excepting expert knowledge on local cropping

631 systems, the choice of length of sequence as observation symbol is also

632 limited to both the temporal depth of data available of land-cover and the

633 computing power. Moreover, we kept 2549 major crop sequences for

634 clustering 406 (merged) agricultural districts. Potentially innovative crop

635 sequences with rare occurrences were not specifically taken into account.

636 The more complex cropping patterns involving winter cover crop,

637 intercropping, etc. could not be investigated in this study since the records

638 of the Teruti survey were carried out every June between 1992 and 2003 and

639 each sampling point represents one land-cover type for a year.

6404.3 Characteristic of the modeling approach and its potential application to

641 other data source of land-cover

642 One remarkable characteristic of this modeling approach is the use of 643 historical national land-cover survey data for identifying crop sequences at a

644 large regional scale. One benefit of using this type of survey data of land-

645 cover with detailed information of crops for exploring crop sequences is its

646 time series continuity at the same location. This time series continuity

647 makes it more possible to couple the information of cropping patterns with

648 other statistics on agriculture (i.e., the national census of agriculture, the

649 survey of the structure of agricultural holdings, the survey of agricultural

650 practices) with fewer problems of time mismatch, further improving the

651 description and assessment of the agricultural production systems.

652 With the development of remote sensing techniques, land-cover data based 653 on the temporal depth of remote sensing imagery is more available.

654 Martínez-Casasnovas et al. (2005) proposed a method of mapping the main 655 multi-year cropping patterns using crop maps which were acquired from 656 supervised classification of Landsat image. The temporal depth of remote 657 sensing imagery is often affected by the quality of the image archive, which 658 suffers reductions of landscape views because of persistent cloud patterns, 
and changes in the remote sensing system (Rindfuss et al., 2004). Several recent researches make progress in crop classification using time-series remotely sensed data for classifying multiyear agricultural land use or investigating the changes in crop rotation patterns at large regional scale (Wardlowet al., 2007; Brown et al., 2013; Plourdeet al., 2013). Thus, if the remotely sensed multi-temporal land-cover data with maximally detailed land-cover types are available, it is possible to perform our modeling approach to describe the past or current crop sequence patterns from regional to global scale. Ideally, if the data of multi-temporal land-cover covering the entire one year growing season for several years is accessible, it will be possible to explore more complex cropping patterns taking into account both the annual main crops and the cover crops. These high temporal-spatial resolution remote sensing data will provide more spatiallytemporally explicit and accurate data for investigating cropping systems.

We emphasize that as the tool we used for extracting crop sequences is a temporal data mining tool, the quality of the corpus of observed sequences strongly influences the model estimation of parameters. Constant and continuous land-cover and use data at the stable location are essential. CARROTAGE is not able to handle the corpus with missing value during the study period, and it is preferable to apply the Hidden Markov Model to large databases.

\section{Conclusions}

The modeling approach of the spatial distribution of crop sequences presented in this study is an empirical modeling combining a temporal regularity data mining tool based on Hidden Markov Model with a classic unsupervised clustering technique on the annual national land-cover survey dataset. The patterns of crop sequences identified here well represent the homogeneity of the major crop sequences within the zone under similar environmental and socio-economic conditions, as well as the heterogeneity of crop sequence patterns across the entire French mainland territory. 
689 This work allows stakeholders such as advisory services, agencies of

690 agriculture and state agricultural organization to evaluate the state of

691 agricultural land use over a long period. They may therefore evaluate their

692 role, as driving forces, on the state of agricultural production systems.

693 For future work, two tasks should be carried out: investigating the changes

694 in crop sequence patterns and exploring the determinants of the changes,

695 linking particularly the relationship between farm types (e.g. the

696 economically based EU Community typology for agricultural holdings) and

697 crop sequence patterns.

698 This modeling approach can be considered as a generic method for

699 modeling the crop sequence patterns using observed land-cover and use data.

700 It is possible to apply it in other cases using other sequential land-cover and

701 use data. It is also possible to perform it at different spatial scales.

702 Regarding the fast growth of investment on the collection of the time series

703 land-cover and use data with categories of crops distinguished by different

704 organizations such as the yearly Land-use/cover area frame statistical survey

705 (LUCAS) funded and launched by Eurostat from 2001, obtaining observed

706 data of cropping patterns becomes possible. However, the large volumes of

707 data of land-cover and use have necessitated the development of innovative

708 data processing and analysis systems for delivering accurate data for global

709 change research.

710 The contribution of our modeling approach is to extract crop sequence from

711 the sequential land-cover and use dataset to provide spatially-explicit data of

712 cropping patterns for the assessment of environmental impacts of

713 agricultural production systems and modeling the agricultural land-use

714 change under the rotational system.

\section{Acknowledgements}

716 The authors gratefully acknowledge the statistic center SSP of the French

717 Ministry of Agriculture for providing the Teruti land-cover and use dataset

718 and the agricultural holding data of OTEX 2000. We also thank the 

are acknowledged.

722

\section{References}

Agreste, 2004. L'utilisation du territoire en 2004 - Nouvelle série 1992 à 2004 Agriculture $n^{\circ} 169$, Paris, 83 p. Agreste, 2010. Grandes cultures-Alternance des cultures, Agreste les Dossiers $n^{\circ}$ 8, 37 p.URL: 〈http://www.agreste.agriculture.gouv.fr/IMG/file/dossier8_cultures_alternan ce.pdf $\rangle$.

Aurbacher, J., Dabbert, S., 2011. Generating crop sequences in land-use models using maximum entropy and Markov chains. Agric. Syst. 104, 470479.

Beaudoin, N., Saad, J., Van Laethem, C., Machet, J., Maucorps, J., Mary, B., 2005. Nitrate leaching in intensive agriculture in Northern France: Effect of farming practices, soils and crop rotations. Agric. Ecosyst. Environ. 111, 292-310.

Brock, G., Pihur, V., Datta, S., Datta, S., 2011. clValid: Validation of Clustering Results. R package version 0.6-4.

Brown, J.C., Kastens, J.H., Coutinho, A.C., Victoria, D.d.C., Bishop, C.R., 2013. Classifying multiyear agricultural land use data from Mato Grosso using time-series MODIS vegetation index data. Remote Sens. Environ. 130, $39-50$.

Castellazzi, M.S., Wood, G.A., Burgess, P.J., Morris, J., Conrad, K.F., Perry, J.N., 2008. A systematic representation of crop rotations. Agric. Syst. 97, 26-33.

Dogliotti, S., Rossing, W.A.H., van Ittersum, M.K., 2003. ROTAT, a tool for systematically generating crop rotations. Eur. J. Agron. 19, 239-250. Eurostat, 2010. Results on EU land ocver and use published for the first time, Land Use/Cover Area frame Survey, 4 
FAOSTAT, 2011. Land-use resources domain in FAOSTAT. Food and

752 Agriculture Organization of the United Nations, Rome, Italy. URL:

753 〈http://faostat.fao.org/site/377/DesktopDefault.aspx?PageID=377\#ancor〉

754 (accessed DATE: 24 May 2012).

755 Graveline, N., Loubier, S., Gleyses, G., Rinaudo, J.D., 2012. Impact of

756 farming on water resources: Assessing uncertainty with Monte Carlo

757 simulations in a global change context. Agric. Syst. 108, 29-41.

758 Herzog, F., Steiner, B., Bailey, D., Baudry, J., Billeter, R., Bukácek, R., De

759 Blust, G., De Cock, R., Dirksen, J., Dormann, C.F., De Filippi, R., Frossard,

760 E., Liira, J., Schmidt, T., Stöckli, R., Thenail, C., van Wingerden, W.,

761 Bugter, R., 2006. Assessing the intensity of temperate European agriculture

762 at the landscape scale. Eur. J. Agron. 24, 165-181.

763 Husson, F., Lê, S., Pagès, J., 2010. Exploratory Multivariate Analysis by

764 Example Using R, Computer Science and Data analysis Series. Chapman \&

765 Hall/CRC, London.

766 Joannon, A., Bro, E., Thenail, C., Baudry, J., 2008. Crop patterns and

767 habitat preferences of the grey partridge farmland bird. Agron. Sustain. Dev.

$768 \quad 28,379-387$.

769 Josse, J., Husson, F., 2012. Selecting the number of components in principal

770 component analysis using cross-validation approximations. Comput. Stat.

771 Data Anal. 56, 1869-1879.

772 Klöcking, B., Strobl, B., Knoblauch, S., Maier, U., Pfutzner, B., Gericke, A.,

773 2003. Development and allocation of land-use scenarios in agriculture for

774 hydrological impact studies. Phys. Chem. Earth 28, 1311-1321.

775 Lambin, E.F., Rounsevell, M.D.A., Geist, H.J., 2000. Are agricultural land-

776 use models able to predict changes in land-use intensity? Agric. Ecosyst.

$777 \quad$ Environ. 82, 321-331. 

for environmental challenges in agriculture. Landsc. Ecol. 25, 169-183.

Le Ber, F., Benoit, M., Schott, C., Mari, J.F., Mignolet, C., 2006. Studying crop sequences with CARROTAGE, a HMM-based data mining software. Ecol. Model. 191, 170-185.

Le Féon, V., Burel, F., Chifflet, R., Henry, M., Ricroch, A., Vaissiere, B.E., Baudry, J., 2013. Solitary bee abundance and species richness in dynamic agricultural landscapes. Agric. Ecosyst. Environ. 166, 94-101.

Lê, S., Josse, J., Husson, F., 2008. FactoMineR: An R package for multivariate analysis. J. Stat. Softw. 25, 1-18.

Lebart, L., Morineau, A., Piron, M., 1995. Statistique exploratoire multidimensionnelle. Dunod, Paris.

Ledoux, M., Thomas, S., 1992. De la photographie aérienne à la production de blé, AGRESTE, la statistique agricole (5).

Leteinturier, B., Herman, J.L., de Longueville, F., Quintin, L., Oger, R., 2006. Adaptation of a crop sequence indicator based on a land parcel management system. Agric. Ecosyst. Environ. 112, 324-334.

Mari, J.F., Le Ber, F., 2006. Temporal and spatial data mining with secondorder hidden markov models. Soft Comput. 10, 406-414.

Martínez-Casasnovas, J.A., Martín-Montero, A., Auxiliadora Casterad, M., 2005. Mapping multi-year cropping patterns in small irrigation districts from time-series analysis of Landsat TM images. Eur. J. Agron. 23, 159-169. Matthews, R.B., Gilbert, N.G., Roach, A., Polhill, J.G., Gotts, N.M., 2007. Agent-based land-use models: a review of applications. Landsc. Ecol. 22, 1447-1459.

Merrill, S.D., Tanaka, D.L., Liebig, M.A., Krupinsky, J.M., Hanson, J.D., Anderson, R.L., 2012. Sequence effects among crops on alluvial-derived soil compared with those on glacial till-derived soil in the northern Great Plains, USA. Agric. Syst. 107, 1-12. 
807 Mignolet, C., Schott, C., Benoit, M., 2007. Spatial dynamics of farming

808 practices in the Seine basin: Methods for agronomic approaches on a

809 regional scale. Sci. Total Environ. 375, 13-32.

810 Miller, F.P., 2008. After 10,000 Years of Agriculture, Whither Agronomy?

811 Agron. J. 100, 22-34.

812 Molnar, I., 2003. Cropping Systems in Eastern Europe: Past, Present, and

813 Future in: Shrestha, A. (Ed. ), Cropping Systems: trends and Advances. The

814 Hawworth Press Inc., New York, pp. 623-647.

815 Mudgal, S., Lavelle, P., 2010. Environmental impacts of different crop

816 rotations in the European Union, Paris, p. 149.URL:

817 〈http://ec.europa.eu/environment/agriculture/pdf/BIO_crop_rotations\%20fin

818 al\%20report_rev\%20executive\%20summary_.pdf $\rangle$

819 Neumann, K., Verburg, P.H., Elbersen, B., Stehfest, E., Woltjer, G.B., 2011.

820 Multi-scale scenarios of spatial-temporal dynamics in the European

821 livestock sector. Agric. Ecosyst. Environ. 140, 88-101.

822 Plourde, J.D., Pijanowski, B.C., Pekin, B.K., 2013. Evidence for increased

823 monoculture cropping in the Central United States. Agric. Ecosyst. Environ.

$824165,50-59$.

825 R Core Team, 2012. R: A language and environment for statistical

826 computing. R Foundation for Statistical Computing, Vienna, Austria.ISBN

827 3-900051-07-0. URL:〈http://www.R-project.org/〉.

828 Richard-Schott, F., 2009. Le Recensement Général de l'Agriculture de 1955,

829 une référence pour les géographes ? Géocarrefour 84, 271-279.

830 Rindfuss, R.R., Walsh, S.J., Turner, B., Fox, J., Mishra, V., 2004.

831 Developing a science of land change: Challenges and methodological issues.

832 Proc. Natl. Acad. Sci. U. S. A. 101, 13976.

833 Rode, M., Thiel, E., Franko, U., Wenk, G., Hesser, F., 2009. Impact of 834 selected agricultural management options on the reduction of nitrogen loads

835 in three representative meso scale catchments in Central Germany. Sci.

836 Total Environ.407, 3459-3472. 
837 Rounsevell, M., Annetts, J., Audsley, E., Mayr, T., Reginster, I., 2003.

838 Modelling the spatial distribution of agricultural land use at the regional

839 scale. Agric. Ecosyst. Environ. 95, 465-479.

840 Salmon-Monviola, J., Durand, P., Ferchaud, F., Oehler, F., Sorel, L., 2012.

841 Modelling spatial dynamics of cropping systems to assess agricultural

842 practices at the catchment scale. Comput. Electron. Agric. 81, 1-13.

843 Schönhart, M., Schmid, E., Schneider, U.A., 2011. Crop Rota - A crop

844 rotation model to support integrated land use assessments. Eur. J. Agron. 34,

$845 \quad 263-277$

846 Schmidt, T.G., Franko, U., Meissner, R., 2008. Uncertainties in large-scale

847 analysis of agricultural land use - A case study for simulation of nitrate

848 leaching. Ecol. Model. 217, 174-180.

849 Temme, A.J.A.M., Verburg, P.H., 2011. Mapping and modelling of changes

850 in agricultural intensity in Europe. Agric. Ecosyst. Environ. 140, 46-56.

851 Therond, O., Hengsdijk, H., Casellas, E., Wallach, D., Adam, M.,

852 Belhouchette, H., Oomen, R., Russell, G., Ewert, F., Bergez, J.-E., Janssen,

853 S., Wery, J., Van Ittersum, M.K., 2011. Using a cropping system model at

854 regional scale: Low-data approaches for crop management information and

855 model calibration. Agric. Ecosyst. Environ. 142, 85-94.

856 Wardlow, B.D., Egbert, S.L., Kastens, J.H., 2007. Analysis of time-series

857 MODIS $250 \mathrm{~m}$ vegetation index data for crop classification in the US

858 Central Great Plains. Remote Sens. Environ. 108, 290-310.

859 Wechsung, F., Krysanova, V., Flechsig, M., Schaphoff, S., 2000. May land 860 use change reduce the water deficiency problem caused by reduced brown

861 coal mining in the state of Brandenburg? Landsc. Urban Plan. 51, 177-189.

862 Wibberley, J., 1996. A brief history of rotations, economic considerations

863 and future directions. Aspects of Applied Biology 0265-1491, 1-10. 


\section{Table captions:}

Table 1

The area of main agricultural landuse in France in 1992 and 2003 (Agreste, 2004).

\section{Table 2}

Result of 5 states left-right HMM2: the main land-cover types of French mainland and their percentage of total frequency at five temporal states between 1992 and 2003. This table shows the evolution of several landcovers such as the expansion of forest, the increase in areas of rapeseed cultivation, the decrease in areas of pea cultivation, etc.

\section{Table 3}

Major land-cover categories of French mainland and their composition between 1992 and 2003.

Table 4

Search pattern for extracting all 3-year LUS involving one given major land-cover category.

Table 5

Internal and stability measurements on different size of clusters to choose an optimal number of clusters for the dataset.

Table 6

Description of the characteristics of 21 clusters based on the v-test value obtained in AHC and the probabilities of occurrences of the 10 most frequent 3-year crop sequences estimated using one-column ergodic HMM2. Nomenclature used is: A (apples), Ap (apricots), B (barley), Bn (beans), Ch (cherries), Fa (fallow), Fo (nut trees), Fs (berry orchard), G (grassland), H (herbaceous vegetation area), Id (industrial crops), M (maize), N (nursery), O (oats), Oc (other cereals), Ol (oilseed crops), Of (other fodder crops), OS (other semi-natural areas including heathland, moors, hedgerow), Ov (other legumes), P (pea), Pa (artificial pasture sown by alfalfa and clover), Pe (peaches), Pl (plums), Pm (alpine meadows), Pr ( pears), Ps (potatoes), 
Pt(temporary pasture), R (rapeseed), Ry( rye), S (sunflower), Sa (6 major species of fruits and crops), Sb (sugar beet), Ss (mixed orchard of 6 major species), St (rocky areas), Tx (fiber crops), V ( vineyards) and W (wheat). CS: crop sequences. AD: agricultural districts. v.test values of variables include both active and supplementary variables.

\section{Figure captions:}

Fig. 1.The economic criteria-based EU community typology for agricultural holdings in France in the year 2000. Data supported by the French Ministry of Agriculture.

Fig. 2.Graphical illustration of the two-level sampling method of the Teruti land-cover survey between 1992 and 2003. (a) The entire territory is segmented into 4700 grids. (b) The position of aerial photos taken in each grid. (c) The distribution of 36 sampling points within an aerial photo. One Teruti sampling point covers roughly 100 hectares.

Fig. 3. Principal component analysis based on the occurrences of 3-year crop sequences across 406 (merged) agricultural districts (AD) during 19922003. (a) PCA score plots of (merged) agricultural districts. (b) PCA loading plots of 3-year crop sequences. Left: on PC1 vs. PC2. Right: on PC3 vs. PC4. For visibility, only the crop sequences whose squared coefficients of correlation between variable and components $>0.5$ for PC1 vs. PC2 and > 0.3 for PC3 vs. PC4 are displayed in plots.

Fig.4. Bar plot of the distance values between the two joining clusters that was used by the Ward's method for hierarchical agglomerative clustering.

Fig. 5. Spatial distribution of 3-year crop sequences in France (overseas departments not included) between 1992 and 2003. Clusters belonging to vineyard-based cropping systems are in the purple series. Clusters belonging to maize monoculture and maize-wheat-based cropping systems are in the orange series. Clusters belonging to temporary pasture and maize-based 
cropping systems are in the grey series. Clusters belonging to wheat and barley-based cropping systems are in the green series.

Fig. 6. Graphic output of CARROTAGE. In order to improve the visibility and to guide the audience, we add a grid to give a coordinate for one landcover in a given year. (a) Original graph: the a posteriori probabilities of transitions between states (diagonal and horizontal lines). Only the transitions whose probability is greater than $0.5 \%$ are displayed; (b) Modified graph with adding a grid to give a coordinate for one land-cover in a given year. 